\title{
Home Automation Android Based GSM System
}

\author{
Miss. Snehal Arun Khulape ${ }^{1}$, Miss. Sakshi Rajendra Malage ${ }^{1}$, \\ Miss. Manasi Sudhir Patil ${ }^{1}$, Miss. Arfa Aslam Bargir ${ }^{1}$, \\ Mr. Sagar V. Chavan ${ }^{2}$ \\ ${ }^{1}$ Student, ${ }^{2}$ Professor \\ Department of Computer Science and Engineering, \\ Sanjay Ghodawat Polytechnic, Atigre, Maharashtra, India
}

\section{ABSTRACT}

The main aim of the project is to develop a system, which uses mobile technology that keep control of the various units of the automobiles, which executes with respect to the signal sent by mobile. In today's time every system is automated in order to face new challenges. Automated system has minimized manual operation, so that the flexibility, reliabilities are found to be highly accurate. Hence every field prefers automated control systems. Specifically in the field of electronics automated systems are proved to be best. Probably the important factor to know about the GSM is that it is an international standard. If you travel around the world, global system for mobile communication is only type of cellular service available in present time. Rather than analog service global system for mobile communication (GSM) was developed as a digital system using TDMA technology. For using devices the unique concept has been about to implement to operate them remotely by using global system for mobile communication , which enables the user to remotely control ON/OFF condition of household appliances. Only a simple SMS sending to the global system for mobile communication modem at nearer place, the devices can be turned ON/OFF and the status of the devices can be sent to the prescribed mobile number registered in the microcontroller. We can control the appliances using mobile. We develop the android app on our mobile. That we can control the any household devices.

Keyword: GSM, Home Automation, TDMA technology

\section{INTRODUCTION}

In 21 st century we are living in where automation is playing an important role in human life. Home automation system helps us to control household devices such as light, door, fan, Air Conditioner etc. Home automation not only refers to minimizing physical efforts but also helps in energy efficiency and is less time consuming. The primary motive of home automation and security system is to control domestic devices by using various techniques like android apps, web pages, global system for mobile communication (GSM) when a person is at distant from home. The system alerts the person in a situation when thieves enters the house by sending SMS on programmed mobile phone which will enable them to protect their home from being stolen. The system also helps older ones by controlling home devices with the help of their mobile phones as they do not need to move physically for turning the appliances $\mathrm{ON}$ or OFF. Important motive of home automation system is to "SAVE ELECTRICITY". With the help of this technology anyone can automatically control the home equipment or office equipment. The system is absolutely secure, easy to handle, reliable, flexible and kindly affordable.

Various techniques have been implemented in order to implement home automation system and security system efficiently. This research paper discusses that Arduino, global systE006D for mobile communication (GSM), and Android based Home Automation and Security System with their implementation. Home Automation system and Security System based on Arduino enwraps that whenever a person will enter the house then number of the persons will get increased, bulb will start 
glowing and alarm will rang. The number of persons available in the room will be displayed on the LCD screen. Whenever the room gets empty then the bulb will automatically stop glowing making the system power efficient. Home Automation system and Security System based on global system for mobile communication (GSM) and Android application enwraps that while a person tries to enter into the house then a SMS will be sent to house owner's mobile phone indicating the presence of some person inside the house and the house owner can take some preventive action to protect his house from the burglar. In most situations the person can operate the home appliances with help of an android app present in the mobile phone which will reduce the human efforts. The list of different home devices along with switching buttons will be provided in an android application. By just touching a particular button enables person to control switching of the home appliances using an Android application.

\section{LITERATURE REVIEW:}

A. International Journal of Engineering Trends and Technology (IJETT) - Volume 47 Number 7 May 2017

Through engineering techniques easy driven, flexible and friendly environment can be achieved. Controllers and sensors are being used for automation purpose. Our main motto is to develop a system that will provide people a living environment with security, convenience, comfort, environmental protection and intelligence and alongside enhancing the lifestyles of people. It will also be locally implemented and maintainable.

B. "Home Automation System Using GSM Technology" - (IJSART - Volume 2 Issue 5 MAY 2016 ISSN)

The main idea of this paper is to control and manage home devices such as fan, light, Ac etc using GSM (Global System for Mobile Communication) Technology which serves and can be used for global. This paper primly aims on the controlling and managing of household devices remotely and providing high integral security. When the user is away from the place of the system, it can be SMS (Short Message Services) i.e., nothing but a plain text message than can be used and uses wireless technology to revolutionize and enhance the standards of living.

\section{OBJECTIVE\& SCOPE:}

\subsection{Existing system}

The design is similar to the existing electrical switches and provides more safety and ease in controlling the switches with low voltage activating method. The switches status is co-occurred in all the control system providing every user interface demonstrates the real time existing switches status. Today's homes require refinement control in its different devices which are nothing but the electronic home appliances. This has mutinous the area of home computerization with respect to an expanded level of affordability, flexibility and simplicity by the assimilation of home appliances with smart phone and tablet connectivity

\subsection{Problem Description}

Modern lifestyle is all about amenity and comfort. So switching off or on the devices by physically moving towards switch board becomes hectic job for people. A person who is physically disabled might be uncomfortable to use switches in the house. Remote controllers can operate a device within the home. If the remote controller gets damaged then we can't control the devices.

\subsection{Objective}

1. One home automation app that has recently started to become popular is the capability to control and manage the home appliances using a Smartphone.

2. This project aims to develop a prototype of a product capable of controlling the devices/appliances, with an emphasis on low cost and open source configurability.

3. The end goal beyond this project would be a product that would hopefully allow people On/off the home appliances using mobile.

\subsection{Proposed work}

We develop the system this system very help full to control the home appliances using mobile. We use the controller Arduino Uno, relay driver, relay, GSM, LCD, power supply .Arduino Uno is the central part of our project we interface the LCD with Arduino Uno also interface GSM \& relay driver. We will make the code for Arduino Uno for control the devices using mobile. in the mobile with android app. In this have on/off button. We press the on button send the SMS our mobile to hardware GSM this signal given to Arduino Uno \& Arduino Uno give the signal to relay driver \& relay driver through relay control the appliances. 


\subsection{Requirements}

\section{Hardware Used}

$>$ Cell phone: Any cell phone with a SIM card can be used through which communication takes place. The communication is achieved through the wireless medium i.e, GSM technology.

> GSM module: GSM module plats a very important role to establish communication between user and system. SIM900A is used. It works at frequency of $900-1800 \mathrm{MHz}$ GSM module receives messages from cell phone and transmits them to the microcontroller.

> ATmega328: ATmega328 is the microcontroller. A microcontroller is the most important component of this system, because it controls the functioning of the home automation system. Its coding is done in Arduino.

$>$ Relays: Role of relays is to perform switching of loads. After receiving the specific command through the phone, microcontroller commands and regulates the relay to switch according to the received command. Transistors are used in parallel with relays when more relays are used, so that switching can be done at low currents.

\section{Software Used}

Proteus: Proteus is used as virtual system modeling and Circuit simulation application. In proteus before actually making the circuits all the circuits are simulated in the Proteus.

$>$ Arduino IDE: The open source Arduino software makes it easy and flexible to write code and then upload it to the microcontroller.

$>$ Android Studio: This software used for develop the android app for devices on/off.

\section{METHODOLOGY:}

\section{Working}

The working of this project is analogously easy; a message is transmitted through the cell phone which has a fixed format. The GSM fragment receives the message and then forwards the same message to the microcontroller. The microcontroller which already has a code saved in it reads and interprets the message and accordingly sends a signal to relays if to open or close according to the command mentioned in the text message.

\section{Block Diagram}

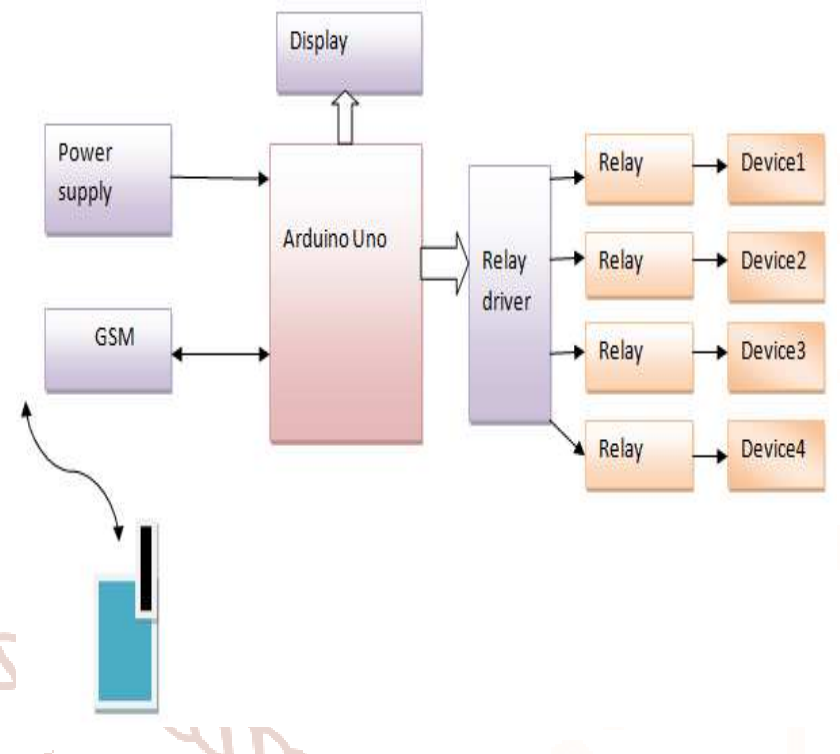

\section{Flow Chart}

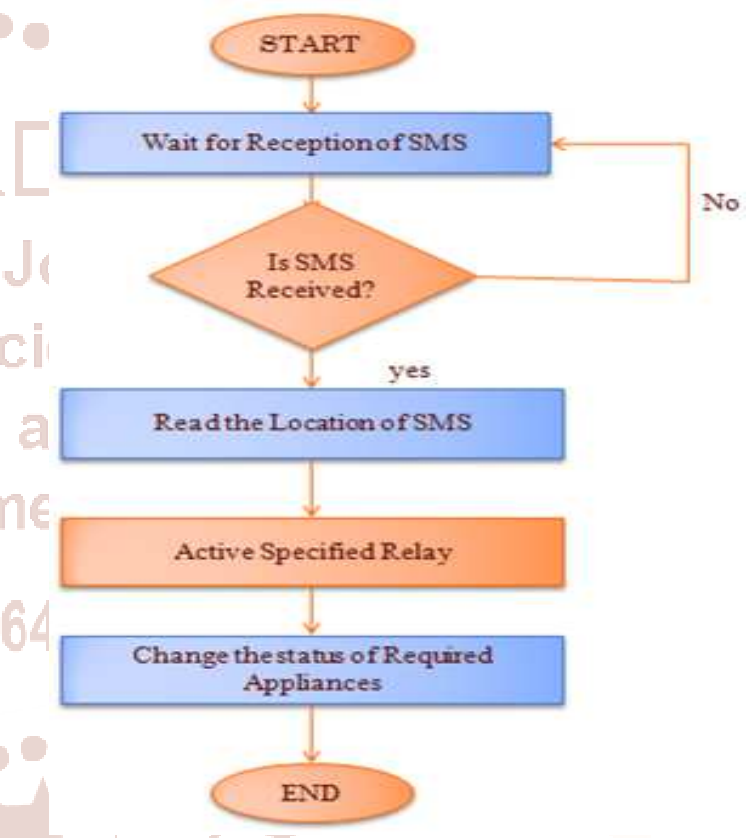

5. ADVANTAGES, APPLICATION:

5.1. Advantages

1. Maximum range using GSM technology

2. User friendly

3. Easy to handle all people

4. Low cost

5. Power saving

\subsection{Disadvantages}

1. If GSM network fails system doesn't work.

\subsection{Application}

1. Home automation.

2. Industrial automation.

3. Lab automation. 


\section{CONCLUSION:}

It can be consummated that "Android based GSM System for Home Automation "was a successfully establishment of a system. This system subsist of an Arduino-Uno board, a Global System for Mobile communication(GSM) Module, a GSM based smart phone, power sockets and home appliances/devices. It is user friendly i.e, flexible to handle, modern and it is mostly a cost effective system. The motto behind this project can be stated in the following points:

$>$ Constructed a wireless home automation system controlled by a GSM based phone.

$>$ Designed and implemented cost effective home automation system which is efficient.

$>$ Designed a user friendly and a safe system to control home appliances especially used by elders and Handicapped.

\section{REFERENCES}

1. A review paper on smart home automation published by Pankaj Bhardwaj (Assistant Professor), ParasManchanda, PrashantChahal, Prashant Chaudhary, Robin Singh Department of ECE, Moradabad Institute of Technology (U.P), India.

2. Home Automation System (HAS) using Android for Mobile Phone Published by Sharon Panth, Mahesh Jivani Shri M \& N Virani Science College, Rajkot-360005 (Gujarat) DeIndia
Department of Electronics, Saurashtra University, Rajkot-360005 (Gujarat) India.

3. Home automation and security system published by Surinder Kaur1, Rashmi Singh, NehaKhairwal and Pratyk Jain Department of Information, BharatiVidyapeeth's College Of Engineering, A-4 PaschimVihar, New Delhi-110063, India.

4. Home Automation System ByBassamRuwaida and Toni Minkkinen.

5. Home Automation System Using Android Application published by Saptarshi Bhowmik, SudipaBiswas, Karan Vishwakarma, Subhankar Chattoraj, Parami Roy.

6. An Introduction to Home Automation from advantech co., Itd., Taiwan from advantech co., ltd., Taiwan from Advantech co., ltd., Taiwan.

7. Android Studio Tutorial For Beginners Part I: https://youtu.be/EknEIzswvC0

8. Android Studio Tutorial For Beginners Part II: https://youtu.be/ZLNO2c7nqjw

9. Android Studio Tutorial For Beginners Part III : : https://youtu.be/EHnJs-9_kzY

10. Anandan, R, Karthik, B, Kumar, K, WIRELESS HOME AUTOMATION SYSTEM USING GSM, Volume 4, No.4, 126-132,2013. 